probable therefore that the flood waters which irrigate Egypt originate in the Atlantic. The small contribution which the rain of the Lake Plateau makes to the Nile flow is put at about 16 per cent of the total flow. The Blue Nile is the great feeder, but the importance for this river of Lake Tana has been exaggerated; other tributaries are more important than the one draining Tana. The waters of the White Nile are dammed up by those of the Blue Nile when the latter is in flood, and much of the White Nile waters then, as at other times also, is lost by evaporation.

Dr. Hurst concludes with some suggestions for improving control of the river. The amount of water lost by evaporation in the Bahr-el-Jebel swamps is enormous. Possible ways of preventing this loss are either by the embankment of the Jebel and the Zeraf to prevent the spilling of water into the marshes, or the construction of a new straight channel outside the swamps into which the flow could be diverted. The loss of water on the Bahr-el-Ghazal Basin also calls for preventive measures. There is also the problem of constructing a dam below Lake Albert in order to use that lake as a storage reservoir. Another among the schemes touched on is the proposal for a power-station at the Aswan Barrage.

\section{PROCEEDINGS OF THE ZOOLOGICAL SOCIETY OF LONDON}

$\mathbf{N}$ the current number of the Proceedings of the Zoological Society, comprising Parts 1 and 2 of Volume 114, the division into two series (A and B) has been discontinued. Accordingly, all papers will now be published in a single annual volume, containing four parts. The issue of the Proceedings in three series, (A) General and Experimental, (B) Systematic and Morphological, and (C) Abstracts of papers communicated at the scientific meetings, was introduced in 1937, and at the same time the practice of giving a serial number to each volume. Previously the volumes were referred to only by the year of issue, which occasionally introduced some uncertainty about the date of publication, since the last part of the volume for any particular year might not appear until January or February in the following year. A further complication arises as a result of the large number of pages contained in the Proceedings of some particular years, which necessitated their being bound in two volumes, and title pages and contents sheets were supplied for this purpose. It thus became necessary to refer to the first or second 'volume' of each year of issue. The use of a serial volume number, which will be printed on all future parts, will obviate this necessity, and simplify bibliographic references to publications in the Proceedings.

The present number comprises ten papers dealing with a wide variety of subjects. F. W. Rogers Brambell has a paper on the reproduction of the wild rabbit, Oryctolagus cuniculus (L.), based on the examination of 957 males, 1,529 females and 1 inter-sex, obtained in Caernarvonshire between February 1941 and June 1942. A very interesting problem arises in connexion with the pre-natal mortality. It is estimated that at least 60 per cent of litters conceived are lost owing to the death and reabsorption of all the embryos, the majority of which die on or about the twelfth day. The mean number of young born to each adult female is found to be between
$10 \cdot 35$ and $11 \cdot 70$ per annum. Ti-Chow Tung and $\mathrm{Yu}$ Fung-Yeh Tung give an account of experiments supporting their view that in the goldfish, Carassius auratus, there exists some centre comparable to the amphibian grey crescent from which the organizer region later arises. R. I. Pocock discusses the races of the North African wild cat. E. J. Popham describes the changes in an aquatic insect population produced by using minnows as predators. A significant difference between the population of three Corixids collected each week was observed, and after the introduction of the minnows the relative proportions of Corixids adapted to the background increased. Robert Gurney deals with the systematics of the crustacean genus Callianassa, and G. H. Findlay describes the development of the auditory ossicles in the elephant shrew, the tenrec and the golden mole. G. P. Wells has a paper emphasizing the inadequacy of our knowledge of even the commonest laboratory animals. The neuropodia and notopodia of Arenicola marina, L., are described in detail, and for working out the anatorny of the intricate musculature the use of polarized light is recommended. L. S. Ramaswami gives an account of the heart and associated vessels in some genera of Apoda, and V. V. Tchernavin gives a revision of the subfamily Orestiinæ and a revision of some Trichomycterinæ, including descriptions of new species based on material preserved in the British Museum, a great part of which was collected by the Titicaca Expedition, of the species of these little-known groups of freshwater fishes.

\section{RUSTY WATER AND MOSQUITO BREEDING}

$\mathrm{W}$ E have received a report by $\mathrm{Mr}$. K. B. Williamson, malaria research officer, Penang (c/o Ross Institute of Tropical Hygiene, London School of Hygiene and Tropical Medicine, W.C.1), on an "Investigation of Ferruginous Waters in relation to the Breeding of Malaria-carrying Mosquitoes". It is a common observation among malariologists in the tropics that waters containing rusty deposits or bearing iridescent surface films of precipitated iron are generally free from mosquito larvæ, and the possibility of utilizing this fact for the control of mosquito breeding has often been mooted. But exact information about the composition of waters of this kind and about the source of the iron has been wanting. Mr. Williamson's report is based on the examination of various types of rusty waters on Hampstead Heath and elsewhere in the neighbourhood of London and around Malvern, as well as upon his experiences in Malaya. It deals mainly with questions of chemistry.

Iron occurs in water: (1) in particulate form as colloidal ferric hydroxide ('iron rust'), the particles being so small that the water is quite clear; it is this colloidal iron which is unstable and readily gives rise to solid aggregates in the form of surface films or precipitates; $(2)$ in true solution as ionized salts of ferrous or ferric iron; (3) as non-ionized organic complexes.

The humic matter derived from the slow rotting of excess vegetation present in soil combines with both ferrous and ferric iron and exerts a stabilizing influence on the colloidal ferric oxide. Humic matter is itself antagonistic to the breeding of most species. 